Article

\title{
Trypanosomatids in Small Mammals of an Agroecosystem in Central Brazil: Another Piece in the Puzzle of Parasite Transmission in an Anthropogenic Landscape
}

\author{
Elida M. V. Brandão ${ }^{1}$, Samanta C. C. Xavier ${ }^{1}$, Jeiel G. Carvalhaes ${ }^{2}$, Paulo S. D'Andrea ${ }^{2}$, \\ Frederico G. Lemos $^{3}(\mathbb{D})$, Fernanda C. Azevedo ${ }^{3}(\mathbb{D})$, Renata Cássia-Pires ${ }^{4}$, Ana M. Jansen ${ }^{1}$ and \\ André L. R. Roque ${ }^{1, *(\mathbb{D})}$ \\ 1 Laboratório de Biologia de Tripanosomatídeos, Instituto Oswaldo Cruz, Fundação Oswaldo Cruz, \\ Rio de Janeiro, RJ 21040900, Brasil; elida_millena@hotmail.com (E.M.V.B.); samanta@ioc.fiocruz.br (S.C.C.X.); \\ jansen@ioc.fiocruz.br (A.M.J.) \\ 2 Laboratório de Biologia e Parasitologia de Mamíferos Silvestres Reservatórios, Instituto Oswaldo Cruz, \\ Fundação Oswaldo Cruz, Rio de Janeiro, RJ 21040900, Brasil; jgabrir@yahoo.com.br (J.G.C.); \\ dandrea@ioc.fiocruz.br (P.S.D.) \\ 3 Programa de Conservação Mamíferos do Cerrado (PCMC)-Unidade Acadêmica Especial de Biotecnologia, \\ Universidade Federal de Goiás/Regional Catalão, Catalão, GO 75704020, Brasil; \\ lemos.pcmc@gmail.com (F.G.L.); cavalcantifer@yahoo.com (F.C.A.) \\ 4 Laboratório de Biologia de Parasitos, Centro de Ciências da Saúde, Departamento de Ciências Farmacêuticas, \\ Universidade Federal do Rio Grande do Norte, Natal, RN 59012570, Brasil; renatacapires@gmail.com \\ * Correspondence: roque@ioc.fiocruz.br; Tel.: +55-21-2562-1416; Fax: +55-21-2562-1609
}

Received: 25 September 2019; Accepted: 11 October 2019; Published: 14 October 2019

\begin{abstract}
We surveyed infection by Trypanosoma spp. and Leishmania spp. in small wild mammals from Cumari, Goiás State aiming to investigate the diversity of trypanosomatid in a modified landscape of the Brazilian Cerrado (and possible infection overlapping with canids from the same area). Blood, skin, spleen, and liver samples were collected for parasitological, serological, and molecular assays. Gracilinanus agilis was the most abundant species $(N=70 ; 48.6 \%)$ and it was the only one with patent parasitemia. Characterization by mini-exon and 18SrDNA targets were achieved in 7/10 hemocultures with positive fresh blood examination, which confirmed the T. cruzi infection by Discrete Typing Units (DTU) TcI in single $(N=2)$ and mixed infections with other DTUs $(N=5)$. T. rangeli and T. dionisii were detected in skin fragments from Didelphis albiventris and Oecomys cleberi, respectively. G. agilis were found to be infected by L. braziliensis and L. guyanensis, while Leishmania sp. DNA was detected in the liver of Oligoryzomys nigripes and Calomys expulsus. Subpatent infection by T. cruzi and Leishmania sp. was serologically detected in 15\% and $9 \%$ of the small mammal fauna, respectively. Small mammals from Cumari are included in T. cruzi and Leshmania spp. transmission cycles, showing a higher diversity of trypanosomatid species and/or genotypes than that observed in canids of the same agroecosystem.
\end{abstract}

Keywords: agroecosystems; Brazilian Cerrado; marsupials; rodents; canids; neotropical mammals; Leishmania sp.; Trypanosoma cruzi

\section{Introduction}

Trypanosoma cruzi and Leishmania spp. (Trypanosomatida; Trypanosomatidae) are enzootic parasites that are maintained in the Americas by dozens of species of mammals and transmitted by hematophagous vector insects, triatomines from the Reduviidae family, and female sandflies from 
Lutzomyia genus, respectively [1,2]. In humans, T. cruzi is the etiological agent of Chagas disease and six Discrete Typing Units (DTU) are currently recognized in this parasite: TcI to TcVI, besides Tcbat, a seventh DTU described in bats [3,4]. Despite proposed attempts to correlate T. cruzi subpopulations with host species, geographic distribution, and/or human disease, it has not yet been possible to detect any unequal association [5].

Leishmania spp. currently comprises more than 30 species, some of which are responsible for distinct clinical forms of human leishmaniasis as zoonotic diseases with high public health impact $[6,7]$. Leishmania species from mammals are divided into two subgenera: L. (Leishmania) and L. (Viannia), which are grouped into eight monophyletic groups that correspond to so-called species complexes [8]. Seven of them: L. donovani, L. mexicana, L. braziliensis, L. lainsoni, L. naiffi, L. lindenberg, and L. guyanensis contain species already described as infecting humans in Brazil [9-12]. Although knowledge of leishmaniasis has improved in recent decades, little is known regarding the spectrum of host species (mammals and vectors) of this parasite in nature [13].

The Cerrado is the second largest Brazilian ecosystem and the second richest savannah biome of the world, containing several endemic species [14,15]; however, it has been suffering human interventions as a result of increasing deforestation for agricultural and livestock occupation [16-18]. The destruction of ecosystems leads to habitat decline, food restriction, and, in some cases, species extinction, leading populations of wild mammals to areas that bring them into contact with humans and domestic animals [19]. It is known that canids may make long displacements, through different types of habitats, such as open areas, forests, and remnants, where small mammals are present and can serve as a food source for them $[20,21]$. Canids may also act as bio-accumulators of parasites, since they are top chain predators [5], and these factors favor the spread of parasites in the environment.

It is in this scenario that the Limoeiro region (Cumari Municipality, Goiás, Brazil) is located, an area of Cerrado quite anthropically altered, where the Mammals from Cerrado Conservation Program (PCMC) develops conservation actions that are focused on endangered species of mammals. In this area, wild canids, such as the hoary fox (Lycalopex vetulus), crab-eating foxes (Cerdocyon thous), and maned wolves (Chrysocyon brachyurus), share the same areas with domestic species (e.g., dogs Canis lupus familiaris and cattle Bos indicus) and humans. Thus, PCMC has been joining multidisciplinary efforts to study aspects, such as ecology, genetics, and health of these animals. As a result of this work, infection by T. cruzi and Leishmania spp. in these wild canids has been diagnosed through serological assays, besides the isolation of T. cruzi DTU TcIII in hoary foxes [22,23]. Aiming to investigate the diversity of trypanosomatid species in the area (and possible infection overlaps among hosts from distinct taxa, as small mammals and canids), we surveyed the infection by Trypanosoma spp. and Leishmania sp. in the small mammal fauna and discuss its association with wild canids that are infected in the same area. We demonstrated a higher diversity of trypanosomatid species and/or genotypes of T. cruzi in small mammals than that observed in canids. We concluded that small mammals from Cumari are immersed in the transmission cycles of T. cruzi and Leshmania spp. and share, at least, one T. cruzi DTU (TcIII) with canids from the same area, showing overlapping transmission cycle among wild canids and small mammals.

\section{Results}

\subsection{Small Mammal Fauna Composition}

One hundred and forty-four small mammals were captured during the four expeditions between 2013 and 2015, totaling a capture success of $2.8 \%$ per trap/night. The number of captured specimens was higher in the dry season $(n=106 ; 73.6 \%)$ than in the wet season $(n=38 ; 26.4 \%)(p=0.0001)$. The abundance of species of marsupials and rodents was similar $(p>0.05)$, with 74 marsupials $(51.4 \%)$ and 70 rodents $(48.6 \%)$ being captured. A greater richness of rodents than marsupials was registered for dry seasons $(p=0.016)$, whereas no difference was detected for wet seasons. The marsupial Gracilinanus agilis was the most abundant species to be captured $(n=70 ; 48.6 \%)$ (Table 1$)$. 
Table 1. Small mammals captured at Limoeiro Region, Municipality of Cumari, Goiás, Brazil, between 2013 and 2015.

\begin{tabular}{cccccc}
\hline \multirow{2}{*}{ Order } & \multirow{2}{*}{ Species } & \multicolumn{4}{c}{ Expedition } \\
\cline { 3 - 6 } & Calomys tener & 1st Dry and Cold & 2nd Wet and Hot & 3rd Dry and Cold & 4th Wet and Hot \\
\hline \multirow{5}{*}{ Rodentia } & Calomys expulsus & 6 & - & 2 & - \\
& Rhipidomys macrurus & 2 & - & 24 & - \\
& Hylaeamys megacephalus & 1 & 2 & 3 & 2 \\
& Oligoryzomys mattogrossae & 1 & 1 & 2 & - \\
& Oecomys cleberi & 1 & - & - & 6 \\
& Necromys lasiurus & - & - & 1 & - \\
& Oligoryzomys nigripes & - & - & 2 & 8 \\
\hline \multirow{3}{*}{ Didelphimorphia } & Total rodents & 17 & 4 & 30 & 22 \\
& Gracilinanus agilis & 17 & 1 & 1 & 23 \\
\hline Total of captures $(n=144) /$ expedition $(n=4)$ & - & 2 & 31 & 31 \\
\hline
\end{tabular}

The ratio of sampling effort in the understory and ground strata was 1600 and 3600, respectively, corresponding to 80 understory traps and 180 ground traps for five nights each excursion $(N=4)$. Capture success was 79 small mammals captured in the understory $(5 \%)$ and 65 captured in the ground stratum (1.8\%). Species, such as G. agilis, D. albiventris, O. cleberi, R. macrurus, and C. tener were also captured in the understory. Thus, out of a total of 106 animals captured of these species, 79 were collected in the understory stratum, which represented $74.5 \%$ of the captured of these species.

\subsection{Trypanosomatid Infection}

One hundred and forty-two specimens were examined by fresh blood examination, and 10 (7\%) of them (all G. agilis) were positive for the presence of flagellates. Of 233 hemocultures that were obtained from 129 small mammals, only one was positive, but it was not established. This culture was derived from one G. agilis also positive in fresh blood examination.

We successfully characterized, by the Mini exon assay, the sediment from seven cultures of the positive samples in fresh blood examination. These were characterized as single infection by $T$. cruzi TCI $(N=3)$ or mixed infection TCI/Z3 (Zymodeme 3) $(N=4)$. The four-mixed infection samples TCI/Z3 were submitted to PCR-RFLP of H3/AluI and two of them were characterized as DTU TcIV (Table 2).

The 18SrDNA nested PCR in all seven samples confirmed Trypanosoma cruzi infection. Of three samples that were characterized as TcI by the mini-exon assay, two confirmed the same DTU and one was identified as TcII, which suggested a mixed infection. Two samples that were suggestive of T. cruzi TcIV were previously characterized as mixed infection by DTUs TcI/TcIV in PCR/RFLP assay. Of the two samples that were characterized as TcI/Z3 in the Mini exon and they were not further characterized by PCR-RFLP of H3/AluI, one was suggestive of infection by TcIII or TcV and another was shown to be infected by $T$. cruzi TcII, also suggesting a mixed infection (Table 3 ).

From 363 skin, spleen, and liver cultures, two skin cultures from a D. albiventris and an O. cleberi were positive. Similarity analysis of PCR products for the $18 \mathrm{~S}$ rDNA gene confirmed the infection by, respectively, T. rangeli (MN381027-100\% identity and 99\% coverage) and T. dionisii ( $99.5 \%$ identity and $100 \%$ coverage), although, in the latter case, it was not possible to make a consensus sequence and parasite identification was based on only one sequence (Table 2).

Molecular diagnosis by kDNA-PCR resulted in four positive samples, all of them in liver fragments that were derived from Calomys expulsus $(N=1)$, Oligoryzomys nigripes $(N=1)$, and G. agilis $(N=2)$. These samples were submitted to PCR targeting HSP70 (234 base pairs) and only the two G. agilis samples were amplified, being identified as L. (V.) braziliensis (MN395479-99.6\% identity and 96\% coverage) e L. (V.) guyanensis ( $97.7 \%$ identity and $98 \%$ coverage). In this latter case, it was not possible to make a consensus sequence and parasite identification was based on only one sequence (Table 2). 
Table 2. Parasitological and molecular diagnosis of captured small mammals at Cumari, Goiás, Brazil.

\begin{tabular}{|c|c|c|c|c|c|c|c|}
\hline \multicolumn{2}{|c|}{ Expeditions/Captured Animals } & \multirow{2}{*}{$\begin{array}{c}\text { 1st Expedition/34 } \\
3\end{array}$} & \multirow{2}{*}{$\begin{array}{c}\text { 2nd Expedition/7 } \\
1^{*}\end{array}$} & \multicolumn{2}{|c|}{ 3rd Expedition/72 } & \multicolumn{2}{|r|}{ 4th Expedition/31 } \\
\hline \multirow{6}{*}{$\begin{array}{c}\text { Positive } \\
\text { parasitological/molecular } \\
\text { diagnosis }\end{array}$} & Fresh blood examination & & & \multicolumn{2}{|c|}{3} & \multicolumn{2}{|r|}{3} \\
\hline & Hemoculture & - & $1^{*}$ & \multicolumn{2}{|l|}{ - } & \multicolumn{2}{|r|}{-} \\
\hline & Skin, spleen or liver culture & - & - & \multicolumn{2}{|c|}{2 SKINS } & \multicolumn{2}{|r|}{-} \\
\hline & $\begin{array}{l}\text { Skin, spleen or liver in } \\
\text { ethanol for kDNA-PCR }\end{array}$ & - & - & \multicolumn{2}{|c|}{ - } & \multicolumn{2}{|r|}{4 LIVERS } \\
\hline & Parasite identification & $\begin{array}{l}\text { TcI }(n=2) \text { and TcI/Z3 } \\
\text { (Discrete Typing Unit - } \\
\text { DTU TcIII/IV) }(n=1)\end{array}$ & $\mathrm{TCI}(n=1)$ & $\begin{array}{l}\text { Blood: TcL/TcIV }(n=2) \\
\text { TcI/Z3 (DTU TcIII/IV) }(n=1)\end{array}$ & $\begin{array}{l}\text { Skin: T. rangeli }(n=1) \\
\text { T. dionisii }(n=1)^{* *}\end{array}$ & $\begin{array}{l}\text { Blood: Not amplified } \\
\qquad(n=3)\end{array}$ & $\begin{array}{l}\text { Liver: Leishmania spp. }(n=2) \text { L. } \\
\text { braziliensis }(n=1) \text { L. guyanensis }(n=1) \text { ** }\end{array}$ \\
\hline & Mammal species & G. agilis $(n=3)$ & G. agilis $(n=1)$ & G. agilis $(n=3)$ & $\begin{array}{l}\text { Didelphis albiventris } \\
\text { (T. rangeli) Oecomys } \\
\text { cleberi (T. dionisii) }\end{array}$ & G. agilis $(n=3)$ & $\begin{array}{l}\text { C. expulsus and O. nigripes ( } n=2 \\
\text { Leishmania spp.) G. agilis (L. braziliensis } \\
\text { and L. guyanensis) }\end{array}$ \\
\hline
\end{tabular}

* Same mammal host. ${ }^{* *}$ It was not possible to make a consensus and the identification of parasite was based only on the reverse sequence.

Table 3. Comparison of results between mini-exon and $18 \mathrm{~S}$ rDNA molecular targets, for characterization of Trypanosoma cruzi infection from hemoculture sediments whose fresh blood examination was positive.

\begin{tabular}{ccc}
\hline ID of Sample & Mini Exon/Restriction Fragment Length Polymorphism Results & Similarity to genBank Sequences by the 18S rDNA Target (Coverage/Identity-\%) * \\
\hline LBCE 15978 & DTU TcI & T cruzi TcI-Reverse Stranded: $96 / 78.86 \%$ \\
LBCE 15979 & DTU TcI/Z3 & T cruzi TcII/TcV-Reverse Stranded: $100 / 83.65 \%$ \\
LBCE 15980 & DTU TcI & T. cruzi TcI-Forward Stranded: $95 / 86.11 \%$ \\
LBCE 18574 & DTU TcI & T. cruzi TcI-Reverse Stranded: $99 / 95.64 \%$ \\
LBCE $18583^{* *}$ & DTU TcI/TcIV & Truzi TcII-Foward Stranded: $97 / 76.38 \%$ \\
LBCE $18584^{* *}$ & & T. cruzi TcIV-Forward Stranded: $100 / 68.03 \%$ \\
LBCE $18586^{* *}$ & DTUTcI/TcIV & T. cruzi TcIV-Reverse Stranded: $98 / 73.19 \%$ \\
T. cruzi TcIV-Forward Stranded: $99 / 72.20 \%$ \\
DTU TcI/Z3
\end{tabular}

* Note: The sequences were analyzed in the BioEdit (Atlanta, GA, USA) and SeqMan (Madison, WI, USA) programs and compared to GenBank sequences only through the Somewhat Similar Sequences (Blastn) tool (National Center for Biotechnology Information, Bethesda, MD, USA), except for LBCE 15979 and LBCE 15980 samples, that it was possible to obtain results from the Megablast (Highly similar sequences). ${ }^{* *}$ These animals were also positive for Trypanosoma lainsoni in blood clot samples [24]. 


\subsection{Serological Diagnosis}

Serology was performed in serum samples of 55 rodents (78.5\% of the captured rodents), with $5.4 \%$ $(N=3)$ infected by $T$. cruzi and 3.6\% $(N=2)$ for Leishmania spp. From the 74 captured marsupials, serology was performed on 68 of them (91.9\%), presenting an infection rate of $14.7 \%(N=10)$ and $2.9 \%$ $(N=2)$ for $T$. cruzi and Leishmania spp., respectively. Mixed infection was observed in $5.4 \%(N=3)$ between rodents and $8.8 \%(N=6)$ among marsupials, as shown in Table 4. Serological diagnosis provides information on a later infection when compared to molecular tests, which indicates that the host had become infected at some point in his life with the parasite, producing IgG class antibodies. This occurs despite the current presence of parasite's DNA, which is unequivocally demonstrated by the molecular tests, indicating the presence of the parasite in that host.

Table 4. Percentage of positivity in the Indirect Immunofluorescent Antibody Test (IFAT) test for Trypanosoma cruzi, Leishmania spp. and mixed infection in small mammals (rodents and marsupials) per expedition.

\begin{tabular}{|c|c|c|c|c|c|c|c|c|}
\hline \multirow[t]{2}{*}{ Infection by } & \multicolumn{2}{|c|}{ 1st Expedition } & \multicolumn{2}{|c|}{ 2nd Expedition } & \multicolumn{2}{|c|}{ 3rd Expedition } & \multicolumn{2}{|c|}{ 4th Expedition } \\
\hline & Rodents & Marsupials & Rodents & Marsupials & Rodents & Marsupials & Rodents & Marsupials \\
\hline T. cruzi (Positive) & $1 / 7(14.3 \%)$ & $4 / 14(28.6 \%)$ & $1 / 4(25 \%)$ & $2 / 3(66.7 \%)$ & $1 / 37(2.7 \%)$ & $4 / 30(13.3 \%)$ & $0 / 7(0 \%)$ & $0 / 20(0 \%)$ \\
\hline Leishmania spp. (Positive) & $0 / 7(0 \%)$ & $1 / 14(7.1 \%)$ & $0 / 4(0 \%)$ & $0 / 3(0 \%)$ & $2 / 37(5.4 \%)$ & $1 / 30(3.3 \%)$ & $0 / 7(0 \%)$ & $0 / 20(0 \%)$ \\
\hline Mixed infection & $2 / 7(28.6 \%)$ & $3 / 14(21.4 \%)$ & $0 / 4(0 \%)$ & $1 / 3(33.3 \%)$ & $1 / 37(2.7 \%)$ & $2 / 30(6.6 \%)$ & $0 / 7(0 \%)$ & $0 / 20(0 \%)$ \\
\hline
\end{tabular}

\section{Discussion}

We demonstrated the small mammal fauna of the Limoeiro region and the most abundant species were Gracilinanus agilis, Calomys expulsus, Oecomys cleberi, and Rhipidomys macrurus. We observed Trypanosoma cruzi infection in Didelphis albiventris, Oecomys cleberi, Rhipidomys macrurus, and G. agilis, with the latter being the only species that displayed patent parasitemia and in which a distinguished diversity of DTUs was detected. We found other trypanosomatid species (T. rangeli, T. dionisii, Leishmania braziliensis, and L. guyanensis) in D. albiventris, O. cleberi, C. expulsus, and G. agilis showing a higher diversity of trypanosomatids in small mammals $(n=9)$ than that observed in wild canids $(n=2)$ of the same area $[23,24]$.

On the ecology of the fauna studied, the higher number of small mammals captured in the dry seasons is probably due to greater availability of food in the rainy season, decreasing the effectiveness of baits and, consequently, capture probability $[25,26]$. Additionally, in the rainy season, most rodent and marsupial populations have few adults and many young, an age class generally less captured in bait traps $[27,28]$. Previous studies in the Cerrado, have detected a high density of rodents during the dry season $[29,30]$, as registered at Limoeiro region, Cumari, most probably because some rodent species present breeding peaks in the rainy season, which leads to an increase in populations during the dry season $[26,31]$. The fourth expedition (wet and hot season) was marked by a capture rate that is similar to the first, probably because the environment could still be influenced by the end of the previous rainy season, which was prolonged in that year (2015). The significant increase in capture rate in the third expedition (dry and cold season) can also be explained by an atypical pluviometric index in the middle of 2014, which might have altered the natural reproductive dynamics of the extant small fauna.

Patent parasitemia by T. cruzi (flagellates in the fresh blood examination and DNA of parasite in hemocultures) were only observed in G. agilis $(7 / 70=10 \%)$, which indicates their competence to infect vectors or other mammals, the last through predation [32]. DNA amplification was not possible for other three samples with flagellates in fresh blood examination. This can be explained, because it is a DNA-poor material (hemoculture sediment), which makes it difficult to recover.

G. agilis was infected by DTU TcI in both single and mixed infections with DTUs TcII, TcIII/TcIV, $\mathrm{TcIV}$, and TcIII/TcV, corroborating that DTU TcI is the genotype most widely dispersed in nature [33,34]. Herein, we provided the first record of DTU TcII in G. agilis in the Cerrado biome, as well as of DTUs 
TcIII and TcIV in this species, showing that DTUs are more widespread both geographically and concerning their host ranges.

DTU TCII is also a widely distributed genotype and it has been found to infect several mammalian taxa in distinct habitats and biomes [35-37]. Although DTUs TcIII and TcIV are widely distributed and may infect a wide variety of mammals, they appear to occur at significantly lower rates, most likely because they are maintained in very low parasitemia in nature, which hampers their detection [23,32]. Although classically associated to armadillos [38,39], T. cruzi TcIII has also proved to be able to infect wild rodents, marsupials, carnivores, and artiodactyls, as well domestic dogs [5,23]. Previous long-term carnivore monitoring studies in the same area (Limoeiro Region, Cumari) registered two hoary foxes (Lycalopex vetulus) that were infected by T. cruzi DTU TcIII [22,23], which indicate the putative share of these DTUs between small mammals and canids of the same area. Finally, it is important to clarify that the finding of TcIII/TcV does not necessarily indicate mixed infection, once 18SrDNA sequences are not useful to separate hybrid genotypes, as is the case of $\mathrm{TcV}$.

We used 18SrDNA target to confirm the results that were obtained by the mini-exon and this approach was useful to: (i) confirm four of the seven results observed in the mini-exon assay; (ii) clarify the DTU of one of the samples infected by Z3 genotype; and, (iii) demonstrate two mixed infections not detected in the mini-exon assay. Thus, $18 \mathrm{~S}$ rDNA confirmed the infection by T. cruzi in all samples positive in the mini-exon assay, although it was not possible to obtain sufficient good quality sequences to make consensus in any of the samples, because it is a DNA-poor material (hemoculture sediment), resulting in sequences presenting not high coverage and identity values. Even if the mini-exon is no more considered as a reliable method for characterizing T. cruzi genotypes, it was useful in this case where the material investigated was poor in DNA, probably due to the higher number of copies in the DNA when compared to $18 \mathrm{~S}$ rDNA target. We confirmed the majority of the DTUs for both targets, except for two samples: one positive for TCI/Z3 and another positive for TCI in the mini-exon, both being characterized as T. cruzi DTU TcII by $18 \mathrm{~S}$ rDNA. This result might indicate a mixed infection by distinct T. cruzi genotypes. Moreover, a study using blood clots from these same samples detected T. lainsoni DNA (a parasite not detectable in the culture medium used) in the G. agilis that were infected by DTU TcI/Z3 [24] demonstrated a polyparasitism by Trypanosoma spp. in this specimen.

Our work also contributed to the first finding of Trypanosoma rangeli in skin cultures. However, the finding of Trypanosoma dionisii must be cautiously analyzed because identification was based on only one sequence of 360 nucleotides. However, once confirmed, this finding also represents the first encounter of this parasite in skin culture, reporting a broader spectrum of tissues that these parasites can be detected in mammals. In fact, in addition to Trypanosoma caninum detected in dog's skin samples, the ability of other trypanosomatid species, such as T. cruzi and T. brucei, to infect the skin has already been demonstrated [40-42]. This is a factor that can explain the transmission of these parasites to vectors, even in the absence of detectable parasitemias. The findings of these two trypanosomatids in the skin suggest that they are: (i) most probably derived from skin microvessels; or, (ii) could be colonizing skin cells, since it is known that $T$ dionisii can invade mammalian cells $[43,44]$. About $T$. rangeli, little is known of its life cycle in mammal hosts, but it has already been found colonizing an unorthodox site (bone marrow) $[45,46]$, so that the colonization of both parasites in the skin cannot be ruled out. These findings may partially explain the transmission mechanism in the absence of high parasitemias. In addition to our findings, [24] evaluated infection by trypanosomatids in blood clots of 33 out of $70 \mathrm{G}$. agilis captured in the same area, identifying the infection by several species of Trypanosoma, including T. dionisii and T. rangeli, showing a larger spectrum of Trypanosoma species circulating in the area that were not found in canids $[23,24]$.

Regarding Leishmania spp. infection in small mammals, there is only one previous record of infection by L. (V.) braziliensis in G. agilis, also in the Brazilian Cerrado (at Minas Gerais state) [47]. However, this is the first report of infection by this parasite in liver samples of this marsupial. Moreover, our work contributes to the finding of L. (V.) guyanensis in G. agilis, although other marsupial species have already been found to be infected by this parasite $[48,49]$, which suggests that, in addition 
to other marsupials, G. agilis is also able to maintain a richness of trypanosomatids. Our register also represents a new geographical area for the distribution of $L .(V$.$) guyanensis, never before registered to$ the Brazilian Cerrado.

In the Americas, more than 40 species of mammals were already described as hosts of Leishmania parasites [50]; however, only a minority of them act as reservoirs, being a source of infection to phlebotomine sand fly vectors; and, thereby, contributing to the dispersion of Leishmania [13,47]. On the other hand, regarding Leishmania infection through the predation of infected mammals, although the oral route has not yet been demonstrated, it is known that amastigotes are capable of infecting mammals, and this is a route that cannot yet be ruled out to occur in nature [51,52].

In addition to G. agilis, the Indirect Immunofluorescent Antibody Test (IFAT) detected infection by T. cruzi and Leishmania spp. in a broader range of local hosts than detected by the other methods, which complements the enzootic scenario by identifying infected individuals that were probably not infective to vectors at that moment (undetectable parasitemia) [32].

It is worth mentioning that most of the G. agilis that were infected by T. cruzi were captured in the understory stratum; however, these marsupials also circulate in the soil, which might favor contact with possible predators. A positive correlation was already demonstrated between T. cruzi infection rates and the proportion of mammals and insects in the diet of wild Carnivores [22], oral transmission being consistently suggested as the main mechanism of dispersion of the parasite among wild mammals $[5,53]$. In the specific case of G. agilis, this marsupial species represents less than $5 \%$ of the diet of wild canids (C. thous, C. brachyurus, and L. vetulus). This indicates that canids in the Limoeiro region do not frequently consume this marsupial [21], especially in the case of hoary fox, which was the species with the highest T. cruzi infection rates in the area. On the other hand, it is worth mentioning that one-time consumption of an infected animal is enough for the canid to become infected during its whole life, especially when considering that the lifetime of canids is about four or five times longer than that of small mammals, which increases the chances of being infected. On the other hand, rodents are consumed at much higher frequencies by the three canine species and they are constantly seen on pastures, areas widely used by these canids [21]. However, the intense heating that could favor death of small mammals inside the traps and the abundance of cattle were factors that impaired our sampling in this environment. For this reason, and knowing that wild canids rarely enter forested habitats, preferring edges of forest fragments and/or open areas of Cerrado [21], transects to capture small mammals were installed at the edges of fragments, or near fragments, and this might have increased the chance of capturing arboreal species, such as G. agilis.

G. agilis has biological and ecological characteristics that favor its exposure to the different transmission cycles of these parasites. This marsupial species presents an omnivorous diet that includes insects [54]; share refuges (such as tree or rocky holes) with triatomines or other insect vectors, besides exploring different forest strata. G. agilis is a representative of the Didelphidae family whose species are considered some of the oldest and most important trypanosomatid reservoirs, already considered as T. cruzi bioaccumulators, due to their ability to host an expressive diversity of trypanosome species [55]. Except for the rare cases of coprophagism and cleptophagism, triatomines become infected while feeding on an infected mammal, for example, an infected G. agilis. Besides the contaminative (T. cruzi) or inoculative (Leishmania spp.) route, the predation of infected small mammals or infected triatomines that acquired the infection by blood-sucking of infected small mammals seems to be the most likely route of T. cruzi infection for canids, revealing that small mammals and canids in that area are participating from the same transmission cycle of T. cruzi. Thus, the small mammals from Cumari are immersed in the transmission cycles of T. cruzi and Leshmania spp. and they share, at least, one T. cruzi DTU (TCIII) with wild canids from the same area. In addition, small mammals showed a higher diversity of Trypanosoma spp., as well as of T. cruzi genotypes, than observed in canids.

The complexity of the transmission cycles of Trypanosoma cruzi and Leishmania spp. in nature involves different components that change over time and space. Therefore, being able to study, in the same area, different elements of wildlife that maintain these parasites in nature provide us with 
complementary information that helps to have a broader understanding. Multidisciplinary work such as this has as its primary objective to contribute to the conservation of mammal species in anthropized areas, and their impacts on human and/or animal health

\section{Materials and Methods}

\subsection{Study Area}

The study area (Figure 1) comprises private cattle farms of the Limoeiro region, in the municipality of Cumari $\left(18^{\circ} 22.02^{\prime} \mathrm{S}, 48^{\circ} 5.48^{\prime} \mathrm{W}\right)$, southeast of Goiás State, Brazil. Most of the area (75\%) has been altered by human activities and it is mostly covered by exotic pasture (Urochloa sp.). Patches of original vegetation (Atlantic Forest and Cerrado), such as gallery and semi-decidous forests, represent the remaining $25 \%$ [56]. The climate in the region has two well-marked seasons, one hot and wet and another cold and dry [57]. We focused on the end of the seasons, also considering rainy periods when they exceed the wet season, to define the collection period. Captures were performed in: (i) August 2013; (ii) April 2014; (iii) September 2014; and, (iv) June 2015. Mean annual temperature and rainfall vary between $22-25^{\circ} \mathrm{C}$ and $1600-1800 \mathrm{~mm}$, respectively (data from Center for Weather Forecast and Climate Studies (CPTEC), National Institute for Space Research (INPE)).

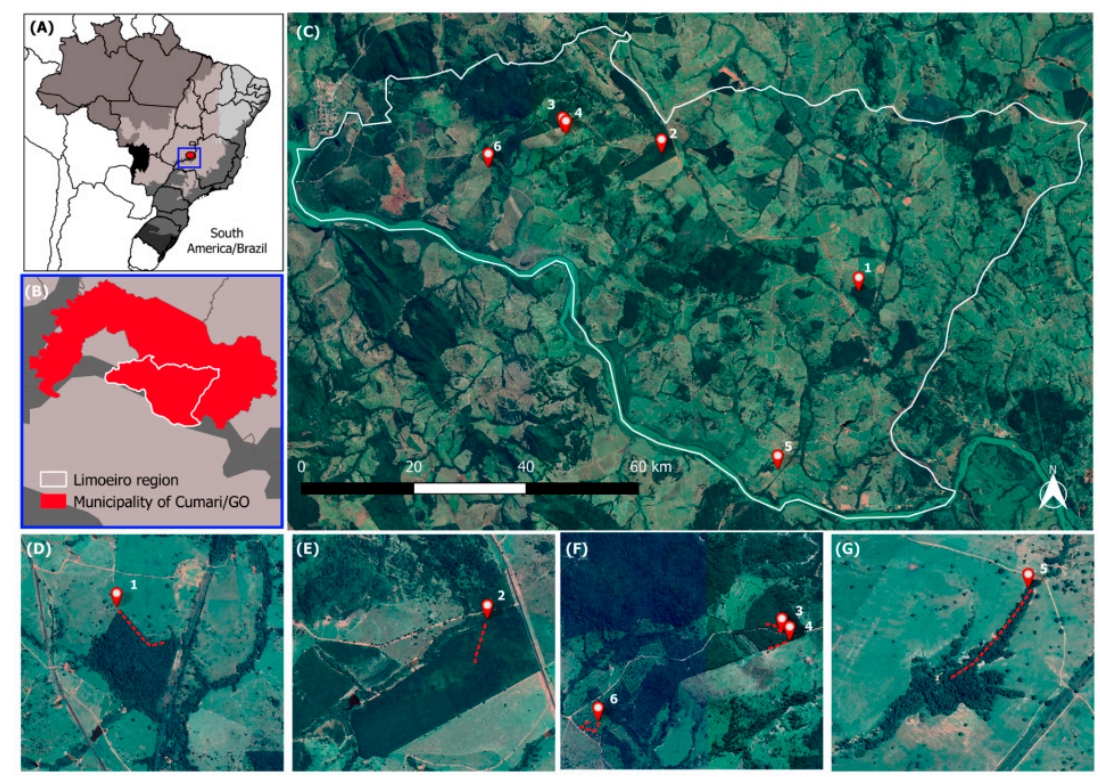

Figure 1. Study area located in the Limoeiro region, municipality of Cumari, southeast of Goiás State, Brazil (A-C), formed by private cattle farms with forest remnants where small mammals were captured. Figures (D-G) show the arrangement of the six transects (1 to 6) at the edges of forest remnants.

\subsection{Small Wild Mammal Capture and Identification}

Small mammals were captured in six transects of 20-40 trap points each, while using live traps (Tomahawk Live Traps, Tomahawk, WI, USA and Sherman-H. B. Sherman Traps, Tallahassee, FL, USA). The traps were disposed at $10 \mathrm{~m}$ intervals during five consecutive nights, alternately distributed both in the ground and understory strata, and baited with a mixture of banana, peanut butter, oat, and bacon or sardines [44]. The transects were placed in areas of riparian and semi-deciduous forests known to be partially used by wild canids (Figure 1). The points of capture of the small mammals were georeferenced through the Global Positioning System receiver (GPS-Montana 650 Garmin ${ }^{\circledR}$ ), with World Geodetic System 84 (WGS 84) as the geodetic reference. The total capture effort was 1300 trap-nights/expedition (totaling 5200 trap-nights during four expeditions). The ratio between sampling effort in the understory and ground strata was 1600/3600 traps, respectively, corresponding 
to 80 traps in the understory and 180 traps on the ground. Whenever a small mammal was captured, the trap was identified, placed in a plastic bag, and then transported to the field laboratory.

The identification of specimens was based on external and cranial morphological characters and on karyological analyses [58]. Euthanized mammals were deposited as vouchers specimens in the Mammal Collection of the National Museum from Rio de Janeiro Federal University (UFRJ), Brazil.

\section{Field Procedures}

The captured small mammals were anesthetized with an intramuscular injection of Ketamine (10-30 mg/kg) associated with: (i) acepromazine $(5-10 \mathrm{mg} / \mathrm{kg}$ ) for rodents (9:1); or, (ii) xylazine ( $2 \mathrm{mg} / \mathrm{kg}$ ) for marsupials (1:1). Blood samples were collected by cardiac puncture for parasitological and serological analysis, as follows: fresh blood examination, hemoculture, and centrifugation to obtain serum.

The fresh blood examination was carried out with a drop of approximately $5 \mu \mathrm{L}$ of blood between slide and coverslip. For hemoculture, it was inoculated $0.6-0.8 \mathrm{~mL}$ of blood from each animal in two tubes (0.3-0.4 mL each) containing Novy-Neal-Nicolle (NNN) medium with Liver Infusion Tryptose (LIT) overlay [22]. Serum was stocked at $-20^{\circ} \mathrm{C}$ for serology assay after blood centrifugation. Priority was given to hemoculture when insufficient blood volume was obtained.

All of the animals were euthanized while using Potassium Chloride $19.1 \%$ by intracardiac route. Samples of skin, spleen, and liver were collected in tubes containing absolute ethanol for Polymerase Chain Reaction (PCR) or sterile saline (sodium chloride- $\mathrm{NaCl}$ at $58.44 \mathrm{~g} / \mathrm{mol}$ ) with antibiotics and antifungals (10 mg streptomycin, $25 \mu \mathrm{L}$ amphotericin $\mathrm{B}$, and 10,000 IU penicillin per $\mathrm{mL}$, Sigma ${ }^{\circledR}$ commercial solution) for culture. After being stored at $4{ }^{\circ} \mathrm{C}$ for $24 \mathrm{~h}$ in this solution, tissue fragments were transferred to culture tubes containing NNN medium and Schneider liquid medium [59].

\subsection{Infection Diagnosis Procedures}

Fresh blood examinations were analyzed in the field laboratory while using an optical microscope at $400 \times$ magnification. Hemocultures were examined every 15 days up to five months [22], while tissue cultures were examined every four days up to two months. Positive tissue cultures and/or hemocultures that were derived from mammals positive in the fresh blood examination (even when negative during the hemoculture examination) were centrifuged for sediment formation and then incubated with proteinase K and Sodium Dodecyl Sulfate (SDS). In this case, the genomic DNA was extracted with the standard phenol-chloroform method [60].

A serological survey for the detection of anti-T.cruzi and anti-Leishmania IgG antibodies was performed while using an Indirect Immunofluorescent Antibody Test (IFAT) [61]. Antigens used in the reaction to $T$. cruzi were an equal mixture of parasites that were derived from the strains M000/BR/1974/F90 (TcI) and MHOM/BR/1950/Y (TcII), obtained from the Collection of Trypanosoma from Wild and Domestic Mammals and Vectors (COLTRYP) of the Oswaldo Cruz Foundation (FIOCRUZ - Rio de Janeiro-RJ/Brazil). Antigens used in Leishmania surveys were an equal mixture from the stains MHOM/BR/1975/M2903 (L. braziliensis-IOC/L566) and MHOM/BR/1974/PP75 (L. infantum-IOC/L579) obtained from the Leishmania Collection from Oswaldo Cruz Institute (CLIOC-FIOCRUZ/RJ).

Serum of Cricetidae rodents were tested with a commercial anti-hamster IgG conjugate (FITC, Sigma-Aldrich ${ }^{\circledR}$, St Louis, MO, USA), whereas marsupials' sera were tested while using intermediary anti-IgG antibodies for Didelphis aurita in rabbits [62]. The reaction was revealed while using an anti-rabbit IgG antibody that was conjugated with fluorescein (Sigma, St Louis, MO, USA). Cutoff values adopted were 1:40 for marsupials and 1:10 for rodents [63].

\subsection{Molecular Diagnosis and Characterization}

Two techniques were used for the molecular characterization of flagellates that were derived from hemocultures. The first one was the Multiplex PCR to amplify the non-transcribed spacer of the mini-exon gene [64]. When positive, the samples were then submitted to the Nested PCR of the 
variable region of the trypanosome $18 \mathrm{~S}$ rDNA gene $[65,66]$. Only the last technique was applied to positive skin cultures.

Multiplex PCR were employed, aiming to amplify the non-transcribed spacer of mini-exon gene for the identification of subtypes TCI (Discrete Typing Units-DTU TcI-200 pb), TCII (DTUs TcII/TcIV/TcV-250 pb), Z3 (DTUs TcIII/TcIV-150 pb), and Trypanosoma rangeli (100 pb) [67], as well as mixed infections. Positive samples for $\mathrm{Z} 3$ were further amplified by PCR for the histone 3 (H3) gene [68], followed by Restriction Fragment Length Polymorphism (RFLP) analysis after digestion by the AluI enzyme for discrimination of TcIII and TcIV [44].

The nested PCR of the variable region of the trypanosome's 18S rDNA gene consists of two rounds: one that amplifies a larger region of the target, using $16 \mathrm{pmol} / \mu \mathrm{L}$ of the primers: TRY927F5' GAAACAAGAAACACGGGAG' and TRY927R-5'CTACTGGGCAGCTTGGA3' , and another where the amplified product of this first round is diluted 1:5 in sterile deionized water and employed in the second round with $16 \mathrm{pmol} / \mu \mathrm{l}$ of the internal primers: SSU561F 5'TGGGATAACAAAGGAGCA3' and SSU561R 5'CTGAGACTGTAACCTCAAAGC3' $[65,66]$.

Electrophoresis of PCR products were carried out in a $\%$ agarose gel, stained with GelRed-Biotium, and then visualized under UV light. Each reaction included sterile distilled water instead of DNA as a negative control and positive control samples from T. cruzi strains that represent the DTUs [22,69].

Tissue fragments that were collected in absolute ethanol were re-hydrated with Nuclease-free water and the DNA extraction was carried out while using the Wizard Genomic DNA Purification Kit (Promega, Madison, USA), according to the manufacturer's recommendations. PCR were performed using the pureTaq Ready-To-Go PCR beads (Amersham Biosciences, Buckinghamshire, $\mathrm{UK}$ ), and primers directed to the conserved region of the Leishmania-kDNA mini circle were: forward: 5'-GGGAGGGGCGTTCTGCGAA-3' and reverse: 5'-GGCCCACTATATTACACCAACCCC-3' [70,71]. The positive and negative controls were derived from spleen and liver fragments from infected (Leishmania braziliensis-IOC-L2483) and non-infected hamsters that were provided by the animal facilities of the FIOCRUZ/RJ. The PCR products were visualized after electrophoresis on $8 \%$ polyacrylamide gel and silver stained while using a specific kit (DNA Silver Staining, GE Healthcare). Positive samples were submitted to another PCR directed to the variable region of the gene coding for the Heat Shock 70 protein (HSP70), a fragment of 234 base pairs, using the following primers (5'-GGACGAGATCGAGCGCATGGT-3') and (5'-TCCTTCGACGCCTCCTGGTTG-3') [70,72]. Samples from this latter target were submitted to purification using DNA purification kit (GE HealthCare Life Sciences, UK) and following the manufacturer's instructions.

The sequencing reaction was performed while using the BigDye Terminator v3.1 kit (Applied Biosystems, USA) and then applied to the ABI3730 DNA analyzer automatic sequencer (Applied) in the Sequencing Platform (RPT01A) of the FIOCRUZ/RJ. The editing and construction of the sequences were performed with the SeqMan-DNA Star Program and the consensus sequences were aligned and edited with the BioEdit Version v7.1.11. Sequence analysis for species identification was performed by similarity that was obtained through Basic Local Alignment Search Tool (BLAST) algorithm against sequences available on GenBank (National Center for Biotechnology Information, NCBI).

\subsection{Statistical Analysis}

Statistical comparisons between the richness and abundance of small mammal species, richness and abundance of species per season, and capture success per seasons were performed using binomial tests on BioEstat 5.0 software (Mamirauá Institute/ Manaus, Amazonas state, Brazil), and a significance level of $5 \%$ was adopted.

\subsection{Ethics Statement}

The handling of the animals was performed according to the biosafety standards established by the Biosafety Commission of the Oswaldo Cruz Institute, IOC/FIOCRUZ following protocols that were 
approved by the Oswaldo Cruz Foundation's Ethics Committee on Animal Use (LW81/12). Capture and euthanasia of wild animals was licensed under SISBIO (13373-1).

\subsection{Map Construction}

For the map construction, the study area and the trailing points of the captured small mammals were visualized in a Geographic Information System (GIS) in the Quantum GIS software version 2.18 , using the continental, national, and municipal boundaries of the study area, extracted from the open access cartographic base of Brazilian Institute of Geography and Statistics (IBGE). Google Earth Satellite images (QGIS QuickMapServices plugin) were also used.

Author Contributions: Conceptualization, E.M.V.B., F.G.L., F.C.A., A.M.J. and A.L.R.R.; formal analysis, E.M.V.B. and S.C.C.X.; funding acquisition, P.S.D., A.M.J. and A.L.R.R.; investigation, E.M.V.B., S.C.C.X., J.G.C., F.G.L., F.C.A., R.C.-P., A.M.J. and A.L.R.R.; methodology, P.S.D., F.G.L., F.C.A., A.M.J. and A.L.R.R.; project administration, A.L.R.R.; Resources, P.S.D., F.G.L., F.C.A., A.M.J. and A.L.R.R., supervision, A.L.R.R.; visualization, E.M.V.B.; writing-original draft, E.M.V.B.; writing-review \& editing, E.M.V.B., S.C.C.X., J.G.C., F.G.L., F.C.A., R.C.-P., A.M.J. and A.L.R.R.

Funding: The study was financially supported by Conselho Nacional de Desenvolvimento Científico e Tecnológico/CNPq (PAPES VII-401764/2015-0) to ALRR and fellowship to EMVB. AMJ and ALRR are "Cientista" and "Jovem Cientista" do Nosso Estado", respectively, provided by Faperj and are financially supported by CNPq ("Bolsista de Produtividade). The funders had no role in the study design, data collection and analysis, decision to publish, or preparation of the manuscript.

Acknowledgments: We want to thank all drivers (FIOCRUZ) and personnel (PCMC) involved in field logistics. The authors also thank Mozart Caetano de Freitas-Junior (PCMC), Camila Lúcio (LABPMSR-IOC), Vitor Araújo, Bruno Alves (LABTRIP/FIOCRUZ/IOC) and Artur Augusto Neto (LAOCLIN DERMZOO/INI/FIOCRUZ) for their invaluable help during fieldwork and collection of animals. We would also like to thank Carlos Ruiz Ardé and Marcos Antônio dos Santos Lima for their technical support in the cultures. Marlon Silva for image editing, as well as André Pereira, Viviane Xavier and Ana Kamilla da Cruz for technical support in the serological exams. We thank Daniele Bilac, Camila Lopes, Maria Augusta Dario, Cristiane Varella, Alice Berbigier, Suellen Sanches and Fernanda Alves for their support in the techniques of mini-exon and 18S rDNA PCR. We are also grateful to Juliana Barros and Marina Rodrigues for the support with their analysis of the sequences and to PDTIS/Fiocruz sequencing platform.

Conflicts of Interest: The authors declare they have no conflict of interest.

\section{References}

1. World Health Organization. Leishmaniasis: Background Information. A Brief History of the Diseases; World Health Organization: Geneva, Switzerland, 2009.

2. Jansen, A.M.; Roque, A.L.R. Domestic and wild mammalian reservoir. In American Trypanosomiasis Chagas Disease-100 Years of Research, 2nd ed.; Telleria, J., Tibayrenc, M., Eds.; Elsevier: London, UK, 2010; pp. $249-276$.

3. Zingales, B.; Andrade, S.G.; Briones, M.R.; Campbell, D.A.; Chiari, E.; Fernandes, O.; Guhl, F.; Lages-Silva, E.; Macedo, A.M.; Machado, C.R.; et al. A new consensus for Trypanosoma cruzi intraspecific nomenclature: Second revision meeting recommends TcI to TcVI. Mem. Inst. Oswaldo Cruz. 2009, 104, 1051-1054. [CrossRef] [PubMed]

4. Marcili, A.; Lima, L.; Cavazzana, M.; Junqueira, A.C.; Veludo, H.H.; Maia Da, S.F.; Campaner, M.; Paiva, F.; Nunes, V.L.; Teixeira, M.M. A new genotype of Trypanosoma cruzi associated with bats evidenced by phylogenetic analyses using SSU rDNA, cytochrome $b$ and Histone H2B genes and genotyping based on ITS1 rDNA. Parasitology 2009, 136, 641-655. [CrossRef] [PubMed]

5. Jansen, A.M.; Xavier, S.C.D.C.; Roque, A.L.R. Trypanosoma cruzi transmission in the wild and its most important reservoir hosts in Brazil. Parasit. Vectors. 2018, 6, 502. [CrossRef] [PubMed]

6. Brasil. Ministério da Saúde. Secretaria de Vigilância em Saúde. Manual de Vigilância e Controle da Leishmaniose Visceral/Ministério da Saúde; Editora do Ministério da Saúde: Brasília, Federal Disctric, Brazil, 2006; 120p.

7. Akhoundi, M.; Downing, T.; Votýpka, J.; Kuhls, K.; Lukeš, J.; Cannet, A.; Ravel, C.; Marty, P.; Delaunay, P.; Kasbari, M.; et al. Leishmania infections: Molecular targets and diagnosis. Mol. Asp. Med. 2017, 57, 1-29. [CrossRef]

8. Fraga, J.; Montalvo, A.M.; de Doncker, S.; Dujardin, J.C.; Van der Auwera, G. Phylogeny of Leishmania species based on the heat-shock protein 70 gene. Infect. Genet. Evol. 2010, 10, 238-245. [CrossRef] 
9. Silveira, F.T.; Souza, A.A.A.; Lainson, R.; Shaw, J.J.; Braga, R.R.; Ishikawa, E.A.Y. Cutaneous leishmaniasis in the Amazon Region: Natural infection of the sandfly Lutzomyia ubiquitalis (Psychodidae: Phlebotominidae) by Leishmania lainsoni in Pará State, Brazil. Mem. Inst. Oswaldo Cruz. 1991, 86, 127-130. [CrossRef]

10. Rangel, E.; Lainson, R. Flebotomíneos do Brasil; Editora da Fiocruz: Rio de Janeiro, Brasil, 2006; p. 360.

11. Lainson, R. Espécies neotropicais de Leishmania: Uma breve revisão histórica sobre sua descoberta, ecologia e taxonomia. Rev. Pan-Amaz. Saúde. 2010, 2, 13-32.

12. Cantanhêde, L.M.; Mattos, C.B.; Ronconi, C.S.; Filgueira, C.P.B.; Silva Júnior, C.F.S.; Limeira, C.; Silva, H.P.J.; Ferreira, G.E.M.; Porrozzi, R.; Ferreira, R.G.M.; et al. First report of Leishmania (Viannia) lindenbergi causing tegumentary leishmaniasis in the Brazilian western Amazon region. Parasite 2019, 26, 1-5. [CrossRef]

13. Roque, A.L.R.; Jansen, A.M. Wild and synanthropic reservoirs of Leishmania species in the Americas. Int. J. Parasitol. Parasites Wildl. 2014, 3, 251-262. [CrossRef]

14. Oliveira-Filho, A.T.; Ratter, J.T. Vegetation physiognomies and woody flora of the cerrado biome. In The Cerrados of Brazil: Ecology and Natural History of Neotropical Savanna; Oliveira, P.S., Marquis, R.J., Eds.; Columbia University Press: New York, NY, USA, 2002; pp. 91-120.

15. Mittermeier, R.A.; Gil, R.P.; Hoffman, M.; Pilgrim, J.; Brooks, T.; Mittermeier, C.G.; Fonseca, G.A.B. Hotspots Revisited: Earth's Biologically Richest and Most Endangered Terrestrial Ecoregions, 2nd ed.; University of Chicago Press: Boston, MA, USA, 2005; p. 200.

16. Klink, C.A.; Machado, R.B. Conservation of the Brazilian Cerrado. Conserv. Biol. 2005, 19, 707-713. [CrossRef]

17. Carvalho, F.M.V.; Marco-Júnior, P.; Ferreira, L.G. The Cerrado into-pieces: Habitat fragmentation as a function of landscape use in the savannas of central Brazil. Biol. Cons. 2009, 142, 1329-1403. [CrossRef]

18. Paglia, A.P.; Fonseca, G.A.B.; Rylands, A.B.; Herrmann, G.; Aguiar, L.M.S.; Chiarello, A.G.; Leite, Y.L.R.; Costa, L.P.; Siciliano, S.; Kierulff, M.C.M.; et al. Lista anotada dos mamíferos do Brasil. In Occasional Papers in Conservation Biology, 2nd ed.; Conservação Internacional: Belo Horizonte, Brasil, 2012; p. 88.

19. Roque, A.L.R.; Jansen, A.M. Importância dos animais domésticos sentinelas na identificação de áreas de risco de emergência de doença de Chagas. Rev. Soc. Bras. Med. Trop. 2008, 41, 191-193.

20. Facure, K.G.; Giaretta, A.A.; Monteiro-Filho, E.L.A. Food habits of the crab-eating fox, Cerdocyon thous, in an altitudinal forest of the Mantiqueira Range, southeastern Brazil. Mammalia 2003, 67, 503-511. [CrossRef]

21. Kotviski, B.M.; Giaretta, K.G.F.; Azevedo, F.C.; Freitas-Junior, M.C.; Lemos, F.G. Trophic niche overlap and resource partitioning among wild canids in an anthropized neotropical ecotone. J. Neotrop. Mamm. 2019, in press.

22. Rocha, F.L.; Roque, A.L.R.; de Lima, J.S.; Cheida, C.C.; Lemos, F.G.; Azevedo, F.C.; Arrais, R.C.; Bilac, D.; Herrera, H.M.; Mourão, G.; et al. Trypanosoma cruzi Infection in Neotropical Wild Carnivores (Mammalia: Carnivora): At the Top of the T. cruzi Transmission Chain. PLoS ONE 2013, 8, e67463. [CrossRef]

23. Barros, J.H.S.; Xavier, S.C.C.; Bilac, D.; Lima, V.S.; Dario, M.A.; Jansen, A.M. Identification of novel mammalian hosts and Brazilian biome geographic distribution of Trypanosoma cruzi TcIII and TcIV. Acta Trop. 2017, 172, 173-179. [CrossRef]

24. Rodrigues, M.S.; Lima, L.; Xavier, S.C.C.; Herrera, H.M.; Rocha, F.L.; Roque, A.L.R.; Teixeira, M.M.G.; Jansen, A.M. Uncovering Trypanosoma spp. diversity of wild mammals by the use of DNA from blood clots. Int. J. Parasitol. Parasites Wildl. 2019, 8, 171-181. [CrossRef]

25. Macclearn, D.; Kohler, J.; Mcgowan, K.J.; Cedeño, E.; Carbone, L.G.; Miller, D. Arboreal and Terrestrial Mammal Trapping on Gigante Peninsula, Barro Colorado Nature Monument, Panama. Biotropica. 1994, 26, 208-213. [CrossRef]

26. Santos-Filho, M.; Silva, D.J.; Sanaiotti, T.M. Variação sazonal na riqueza e na abundância de pequenos mamíferos, na estrutura da floresta e na disponibilidade de artrópodes em fragmentos florestais no Mato Grosso, Brasil. Biota Neotrop. 2008, 8, 115-121. [CrossRef]

27. Vieira, M.V. Dynamics of a rodent assemblage in a Cerrado of Southeast Brazil. Rev. Bras. Biol. 1996, $57,99-107$.

28. Quental, T.B.; Fernandez, F.A.S.; Dias, A.T.C.; Rocha, F.S. Population dynamics of the marsupial Micoureus demerarae in small fragments of Atlantic Coastal Forest in Brazil. J. Trop. Ecol. 2001, 17, 339-352. [CrossRef]

29. Mello, D.A. Estudo populacional de algumas espécies de roedores do Cerrado (Norte do Município de Formosa, Goiás). Rev. Bras. Biol. 1980, 40, 843-860. 
30. Alho, C.J.R.; Strüssmann, C.; Volpe, M.; Sonoda, F.; Marques, A.A.B.; Schneider, M.; Santos Junior, T.S.; Marque, S.R. Conservação da Biodiversidade da Bacia do Alto Paraguai-Monitoramento da Fauna Sob Impacto Ambiental; Editora UNIDERP: Campo Grande, Brasil, 2003; p. 449.

31. Reis, N.R.; Peracchi, A.L.; Pedro, W.A.; Lima, I.P. Mamíferos do Brasil; Biblioteca Central da Universidade Estadual de Londrina: Paraná, Brasil, 2006; p. 439.

32. Jansen, A.M.; Xavier, S.C.D.C.; Roque, A.L.R. The multiple and complex and changeable scenarios of the Trypanosoma cruzi transmission cycle in the sylvatic environment. Acta Trop. 2015, 151, 1-15. [CrossRef] [PubMed]

33. Miles, M.A.; Llewellyn, M.S.; Lewis, M.D.; Yeo, M.; Baleela, R.; Fitzpatrick, S.; Gaunt, M.W.; Mauricio, I.L. The molecular epidemiology and phylogeography of Trypanosoma cruzi and parallel research on Leishmania: Looking back and to the future. Parasitology 2009, 136, 1509-1528. [CrossRef]

34. Zingales, B.; Miles, M.A.; Campbell, D.A.; Tibayrenc, M.; Macedo, A.M.; Teixeira, M.M.; Schijman, A.G.; Llewellyn, M.S.; Lages-Silva, E.; Machado, C.R.; et al. The revised Trypanosoma cruzi subspecific nomenclature: Rationale, epidemiological relevance and research applications. Infect. Genet. Evol. 2012, 12, 240-253. [CrossRef]

35. Shikanai-Yasuda, M.A.; Carvalho, N.B. Oral transmission of Chagas disease. Clin. Infect. Dis. 2012, 54, 845-852. [CrossRef]

36. Lima, V.S.; Xavier, S.C.C.; Maldonado, I.F.R.; Roque, A.L.R.; Vicente, A.C.P.; Jansen, A.M. Expanding the knowledge of the geographic distribution of Trypanosoma cruzi TcII and TcV/TcVI genotypes in the Brazilian Amazon. PLoS ONE. 2014, 9, e116137. [CrossRef]

37. Herrera, C.P.; Licon, M.H.; Nation, C.S.; Jameson, S.B.; Wesson, D.M. Genotype diversity of Trypanosoma cruzi in small rodents and Triatoma sanguisuga from a rural area in New Orleans, Louisiana. Parasit Vectors 2015, 8, 123. [CrossRef]

38. Miles, M.A.; Povoa, M.M.; de Souza, A.A.; Lainson, R.; Shaw, J.J.; Ketteridge, D.S. Chagas's disease in the Amazon Basin: Ii. The distribution of Trypanosoma cruzi zymodemes 1 and 3 in Para' State, north Brazil. Trans. R. Soc. Trop. Med. Hyg. 1981, 75, 667-674. [CrossRef]

39. Lisboa, C.V.; Xavier, S.C.; Herrera, H.M.; Jansen, A.M. The ecology of the Trypanosoma cruzi transmission cycle: Dispersion of zymodeme 3 (Z3) in wild hosts from Brazilian biomes. Vet. Parasitol. 2009, 165, $19-24$. [CrossRef]

40. Madeira, M.F.; Almeida, A.B.; Barros, J.H.; Oliveira, T.S.; Sousa, V.R.; Alves, A.S.; Miranda, L.F.; Schubach, A.O.; Marzochi, M.C. Trypanosoma caninum, a new parasite described in dogs in Brazil: Aspects of natural infection. J. Parasitol. 2014, 100, 231-234. [CrossRef] [PubMed]

41. Capewell, P.; Cren-Travaillé, C.; Marchesi, F.; Johnston, P.; Clucas, C.; Benson, R.A.; Gorman, T.A.; Calvo-Alvarez, E.; Crouzols, A.; Jouvion, G.; et al. The skin is a significant but overlooked anatomical reservoir for vector-borne African trypanosomes. eLife 2016, 5, 1-17. [CrossRef] [PubMed]

42. Lewis, M.D.; Francisco, A.F.; Jayawardhana, S.; Langston, H.; Taylor, M.C.; Kelly, J.M. Imaging the development of chronic Chagas disease after oral transmission. Sci Rep. 2018, 1, 8. [CrossRef] [PubMed]

43. Oliveira, M.P.; Cortez, M.; Maeda, F.Y.; Fernandes, M.C.; Haapalainen, E.F.; Yoshida, N.; Mortara, R.A. Unique behavior of Trypanosoma dionisii interacting with mammalian cells: Invasion, intracellular growth and nuclear localization. Acta Trop. 2009, 110, 65-74. [CrossRef]

44. Dario, M.A.; Rodrigues, M.S.; Barros, J.H.; Xavier, S.C.; D'Andrea, P.S.; Roque, A.L.R.; Jansen, A.M. Ecological scenario and Trypanosoma cruzi DTU characterization of a fatal acute Chagas disease case transmitted orally (Espírito Santo state, Brazil). Parasit. Vectors 2016, 9, 477. [CrossRef]

45. De Araújo, V.A.; Boité, M.C.; Cupolillo, E.; Jansen, A.M.; Roque, A.L. Mixed infection in the anteater Tamandua tetradactyla (Mammalia: Pilosa) from Pará State, Brazil: Trypanosoma cruzi, T. rangeli and Leishmania infantum. Parasitology 2013, 140, 455-460. [CrossRef]

46. Stoco, P.H.; Talavera-López, C.W.G.; Gerber, A.; Zaha, A.; Thompson, C.E. Genome of the Avirulent Human-Infective Trypanosome-Trypanosoma rangeli. PLoS Negl. Trop. Dis. 2014, 8,1-17. [CrossRef]

47. Quaresma, P.F.; Rego, F.D.; Botelho, H.A.; da Silva, S.R.; Moura Junior, A.J.; Neto, R.G.T.; Madeira, F.M.; Carvalho, M.B.; Paglia, A.P.; Melo, M.N.; et al. Wild, synanthropic and domestic hosts of Leishmania in an endemic area of cutaneous leishmaniasis in Minas Gerais State, Brazil. Trans. R. Soc. Trop. Med. Hyg. 2011, 105, 579-585. [CrossRef] 
48. Arias, J.R.; Naiff, R.D.; Miles, M.A.; de Souza, A.A. The opossum, Didelphis marsupialis (Marsupialia: Didelphidae), as a reservoir host of Leishmania braziliensis guyanensis in the Amazon Basin of Brazil. Trans. R. Soc. Trop. Med. Hyg. 1981, 75, 537-541. [CrossRef]

49. Dedet, J.P.; Gay, F.; Chatenay, G. Isolation of Leishmania species from wild mammals in French Guiana. Trans. R. Soc. Trop. Med. Hyg. 1989, 83, 613-615. [CrossRef]

50. Oliveira, F.S.; Pirmez, C.; Pires, M.Q.; Brazil, R.P.; Pacheco, R.S. PCR-based diagnosis for detection of Leishmania in skin and blood of rodents from an endemic area of cutaneous and visceral leishmaniasis in Brazil. Vet. Parasitol. 2005, 129, 219-227. [CrossRef] [PubMed]

51. Spotin, A.; Parvizi, P. Comparative study of viscerotropic pathogenicity of Leishmania major amastigotes and promastigotes based on identification of mitochondrial and nucleus sequences. Parasitol. Res. 2015, 115, 1221-1228. [CrossRef] [PubMed]

52. Lainson, R.; Ishikawa, E.A.Y.; Silveira, F.T. American visceral leishmaniasis: Wild animal hosts. Trans. R. Soc. Trop. Med. Hyg. 2002, 96, 630-663. [CrossRef]

53. Roque, A.L.R.; Xavier, S.C.; da Rocha, M.G.; Duarte, A.C.; D'Andrea, P.S. Trypanosoma cruzi transmission cycle among wild and domestic mammals in three areas of orally transmitted Chagas disease outbreaks. Am. J. Trop. Med. Hyg. 2008, 79, 742-749. [CrossRef]

54. Lessa, L.G.; Costa, F.N. Diet and seed dispersal by five marsupials (Didelphimorphia, Didelphidae) in a Brazilian cerrado reserve. Mamm. Biol. 2010, 75, 10-16. [CrossRef]

55. Roman, F.; Iñiguez, A.M.; Yeo, M.; Jansen, A.M. Multilocus sequence typing: Genetic diversity in Trypanosoma cruzi I (TcI) isolates from Brazilian didelphids. Parasit Vectors 2018, 11, 107. [CrossRef]

56. Lemos, F.G. Ecologia e Conservação da Raposa-do-Campo (Lycalopex vetulus) e Suas Interações com Canídeos Simpátricos em Áreas Antropizadas de Cerrado do Brasil Central. Ph.D. Thesis, Universidade Federal de Uberlândia, UFU, Brasil, 2016.

57. Alvares, C.A.; Stape, J.L.; Sentelhas, P.C.; Moraes Gonçalves, J.L.; Sparovek, G. Koppen's climate classification map for Brazil. Meteorol. Z. 2013, 22, 711-728. [CrossRef]

58. Bonvicino, C.R.; Otazu, I.B.; D'andrea, P.S. Karyologic evidence of diversification of the genus Thrichomys (Rodentia, Echimyidae). Cytogenet Genome Res. 2002, 97, 200-204. [CrossRef]

59. Campos, M.P.; Silva, D.A.; Madeira, M.F.; Júnior, A.A.M.V.; Figueiredo, F.B. First autochthonous case of canine visceral leishmaniasis in Volta Redonda, Rio de Janeiro, Brazil. Ver. Bras. Parasitol. Vet. 2013, 3, 424-426. [CrossRef]

60. Sambrook, J.; Fritsch, E.F.; Maniatis, T. Molecular Cloning: A Laboratory Manual, 2nd ed.; Cold Spring Harbor Laboratory Press: New York, NY, USA, 1989; p. 1626.

61. Camargo, M.E. Fluorescent antibody test for the serodiagnosis of American trypanosomiasis. Technical modification employing preseved culture forms of Trypanosoma cruzi in a slide test. Ver. Inst. Med. Trop. S. Paulo. 1966, 8, 227-235.

62. Jansen, A.M.; Moriearty, P.L.; Castro, B.G.; Deane, M.P. Trypanosoma cruzi in the opossum Didelphis marsupialis: An indirect fluorescent antibody test for the diagnosis and follow-up of natural and experimental infections. Trans. R. Soc. Trop. Med. Hyg. 1985, 79, 474-477. [CrossRef]

63. Roque, A.L.; Xavier, S.C.; Gerhardt, M.; Silva, M.F.; Lima, V.S.; D’Andrea, P.S.; Jansen, A.M. Trypanosoma cruzi among wild and domestic mammals in different areas of the Abaetetuba municipality (Pará State, Brazil), an endemic Chagas disease transmission area. Vet. Parasitol. 2013, 193, 71-77. [CrossRef] [PubMed]

64. Fernandes, O.; Santos, S.S.; Cupolillo, E.; Mendonca, B.; Derre, R.; Junqueira, A.C.V.; Santos, L.C.; Sturm, N.R.; Naiff, R.D.; Barret, T.V.; et al. A Mini exon multiplex polymerase chain reaction to distinguish the major groups of Trypanosoma cruzi and T. rangeli in the Brazilian Amazon. Trans. R. Soc. Trop. Med. Hyg. 2001, 95, 97-99. [CrossRef]

65. Noyes, H.A.; Stevens, J.R.; Teixeria, M.; Phelan, J.; Holz, P. A nested PCR for the ssrRNA gene detects Trypanosoma binney in the platypus and Trypanosoma sp. in wombats and kangaroos in Australia. Int. J. Parasitol. 1999, 29, 331-339. [CrossRef]

66. Smith, A.; Clark, P.; Averis, S.; Lymbery, A.J.; Wayne, A.F.; Morris, K.D.; Tompson, R.C. Trypanosomes in a declining species of threatened Australian marsupial, the brush-tailed bettong Bettongia penicillata (Marsupialia: Potoroidae). Parasitology 2008, 135, 1329-1335. [CrossRef] [PubMed]

67. Aliaga, C.; Breniere, S.F.; Barnabe, C. Further interest of miniexon multiplex PCR for a rapid typing of Trypanosoma cruzi DTU groups. Infect. Genet. Evol. 2011, 11, 1155-1158. [CrossRef] [PubMed] 
68. Westenberger, S.J.; Barnabe, C.; Campbell, D.A.; Sturm, N.R. Two hybridization events define the population structure of Trypanosoma cruzi. Genetics 2005, 171, 527-543. [CrossRef]

69. Dario, M.A.; Moratelli, R.; Schwabl, P.; Jansen, A.M.; Llewellyn, M.S. Small subunit ribosomal metabarcoding reveals extraordinary trypanosomatid diversity in Brazilian bats. PLoS Negl. Trop. Dis. 2017, 11, 1-15. [CrossRef]

70. Degrave, W.; Fernandes, O.; Campbell, D.; Bozza, M.; Lopes, U. Use of molecular probes and PCR for detection and typing of Leishmania-A mini-review. Mem. Inst. Oswaldo Cruz. 1994, 89, 463-469. [CrossRef]

71. Cássia-Pires, R.; Boité, M.C.; D’Andrea, P.S.; Herrera, H.M.; Cupolillo, E.; Jansen, A.M.; Roque, A.L.R. Distinct Leishmania Species Infecting Wild Caviomorph Rodents (Rodentia: Hystricognathi) from Brazil. PLoS Negl. Trop. Dis. 2014, 8, 1-8. [CrossRef]

72. Graça, G.C.; Volpini, A.C.; Romero, G.A.S.; Neto, M.P.O.; Hueb, M.; Porrozi, R.; Boité, M.C.; Cupolillo, E. Development and validation of PCR-based assays for diagnosis of American cutaneous leishmaniasis and identification of the parasite species. Mem. Inst. Oswaldo Cruz. 2012, 107, 664-667. [CrossRef] [PubMed]

(C) 2019 by the authors. Licensee MDPI, Basel, Switzerland. This article is an open access article distributed under the terms and conditions of the Creative Commons Attribution (CC BY) license (http://creativecommons.org/licenses/by/4.0/). 